\title{
ASSESSMENT OF THE TROPHIC STATE AND ChLOROPHYLl-A CONCENTRATIONS USING LANDSAT OLI IN KARAOUN RESERVOIR, LEBANON
}

\author{
Ali Fadel, Ghaleb Faour and Kamal Slim ${ }^{1}$ \\ National Center for Remote Sensing, National Council for Scientific Research, P.O. Box: 11- \\ 8281, Riad El Solh, 11072260 Beirut, Lebanon \\ ${ }^{1}$ Lebanese Atomic Energy Commission, National Council for Scientific Research, P.O. Box: \\ 11-8281, Riad El Solh, 11072260 Beirut, Lebanon \\ afadel@cnrs.edu.lb
}

(Received 6 April 2016 - Accepted 21 June 2016)

\section{ABSTRACT}

Fadel, A., Faour, G. and Slim K. 2016. Assessment of the trophic state and chlorophyll-a concentrations using Landsat OLI in Karaoun reservoir, Lebanon. Lebanese Science Journal, 17(2): 130-145.

Harmful algal blooms have become a worldwide environmental problem. A regular and cost-effective monitoring of these blooms is highly needed by lakes managers. Satellite remote sensing imagery like Landsat Operational Land Imager (OLI) can be used to assess and monitor chlorophyll-a in water bodies over large areas in a cost-effective way. In this study, the accuracy of Landsat OLI to estimate chlorophyll-a was examined. Four field campaigns and cloud free images of Landsat OLI with $30 \mathrm{~m}$ resolution (01 May 2013, 21 August 2013, 10 July 2015, and 11 August 2015) were used in this study to determine the accuracy of Landsat OLI in estimating chlorophyll-a in a $12 \mathrm{~km}^{2}$ freshwater body, Karaoun reservoir. After atmospheric correction of these images, reflectance of single and multiple band combinations were compared to field chlorophyll-a data. Results of field campaigns showed that the trophic state of Karaoun reservoir is still eutrophic to hypereutrophic with high nutrient concentration and low phytoplankton biodiversity, dominated by cyanobacteria species, Microcystis aeruginosa and Aphanizomenon ovalisporum. On single band level, the in situ chlorophyll-a measurement correlated best with band $5(0.85-0.88 \mu \mathrm{m})$, with $R=0.75$ and $R^{2}=0.57$. Highest correlation $\left(R=0.84\right.$ and $\left.R^{2}=0.72\right)$ was obtained using band combination, B2:B4 band ratio multiplied by B5. Results indicated that Landsat OLI can be used effectively to determine chlorophyll-a concentration in lakes and reservoirs. We recommend the application of Landsat OLI as a satisfactory and cost effective method for monitoring chlorophyll-a in other lakes through-out the world.

Keywords: Landsat OLI, chlorophyll-a, linear regression analysis, trophic state, case II waters, phytoplankton, algorithms

http://dx.doi.org/10.22453/LSJ-017.2.130145

National Council for Scientific Research - Lebanon 2016® lsj.cnrs.edu.lb/vol-17-no-2-2016/ 


\section{INTRODUCTION}

Lakes and reservoirs are valuable resources that meet human needs for drinking water supply, agricultural irrigation, power generation, industrial use, commercial fishing and recreational activities. Fertilizers and untreated sewage in the catchments of reservoirs pollute these ecosystems by increasing nutrient concentrations and result in their eutrophication (Smith \& Schindler, 2009). Eutrophication threatens freshwater bodies as it promotes the development and the persistence of harmful algal blooms. These blooms reduce the ecosystem biodiversity and can produce toxins (Brient et al., 2009). These toxins has various impact ranging from skin irritation upon contact to intoxication and death when ingested (Nyakairu et al., 2010; Azevedo et al., 2002).

In the European Union, the phytoplankton community is used as a biological indicator of the quality and ecological status of water bodies monitored in accordance with the Water Framework Directive (European Parliament Council, 2000). In addition, the World Health Organization (WHO) has established guideline values for drinking-water supplies and recreational waters which may contain harmful algal blooms (Chorus, 2005).

Chlorophyll is the pigment used to asses algal blooms. It can be measured by traditional in situ sampling methods coupled with laboratory measurements and analyses. However, these methods are often limited in both time and space, and are expensive and time consuming. Remote sensing can be a key tool for assessing and monitoring chlorophyll in water bodies as it allows frequent surveys over large areas in a cost-effective way. Many studies have affirmed temporal and spatial advantages of remote sensing techniques in monitoring and assessing over traditional monitoring methods (Kabenge et al., 2016; Song et al., 2013; Wu et al., 2013).

Most of the high spatial resolution space-borne missions are devoted to land applications, lacking appropriate wavelengths or bandwidths for water purposes. SeaWiFS, MODIS and MERIS are some of space-borne missions that have been used for quantitative monitoring of chlorophyll-a concentration (Bresciani et al., 2013). They are known for their precision because of their high spectral resolution (King et al., 1992; Rast et al., 1999). However, the applications of those sensors were restricted to the open ocean case 1 waters whose optical properties are determined primarily by phytoplankton and related colored dissolved organic matter (CDOM) and detritus degradation products. This cannot satisfy the needs of monitoring the water quality in coastal case 2 waters or inland waters, whose optical properties are significantly influenced by other constituents such as mineral particles, CDOM, or microbubbles, whose concentrations do not co-vary with the phytoplankton concentration (Gerace \& Schott, 2009; Odermatt et al., 2010). They cannot show the detailed spatial pattern at sub-mesoscale due to their low spatial resolution, therefore their usefulness for small to medium-size lakes has been limited (Wu et al., 2008).

Landsat missions provide high spatial resolution with lower spectral resolution. Landsat 8 OLI has been lunched in 11 February 2013. It has more advantage on the previously launched Landsat-7 TM after the use of push-broom scanner and the addition of two new spectral bands, band 1 for coastal water and aerosol, and band 9 for cirrus cloud detection to its OLI sensor (Irons et al., 2012; Li et al., 2013). 
The high spatial resolution and the added bands of Landsat 8 OLI sensor has offered a great promise for case 2 water status quality monitoring (Gerace \& Schott, 2009). Up to our knowledge little or no studies have been performed to determine the accuracy of Landsat OLI in estimating water quality parameters, particularly chlorophyll-a. Some studies have been conducted using the Landsat $7 \mathrm{TM}$ that has fewer bands and uses whisk-broom scanner, but most of these study were limited to a narrow range of chlorophyll-a concentration, often less than $50 \mu \mathrm{g} . \mathrm{L}^{-1}$. This study, 1) examines the accuracy of Landsat OLI estimating chlorophyll-a over a wide range of concentrations, 2) assesses the spatial distribution of chlorophyll-a, and 3) determines the trophic state of Karaoun reservoir in summer 2015.

\section{MATERIALS AND METHODS}

\section{Study site}

Karaoun reservoir, also known as Qaroun, Qaraoun or Qarun, located in the southern part of the Bekaa valley, between the two Lebanese mountain chains, is the largest freshwater body in Lebanon (Figure 1). It has a surface area of $12 \mathrm{~km}^{2}$, maximum depth of 60 $\mathrm{m}$ and a maximum volume of $224 \times 10^{6} \mathrm{~m}^{3}$. The reservoir was constructed between 1958 and 1965 on the Litani River (170 km length) for power production and irrigation. The river inflow occurs mainly in the wet season, from October to April, while the withdrawals are much more regular in the year, which causes a large water level variation in the year, and can reach up to $30 \mathrm{~m}$ (Fadel et al., 2015). No spatial measurements of chlorophyll-a or remote sensing studies on the water quality were conducted before on this reservoir. Studies have been carried out in Karaoun reservoir on toxins and metal and nutrient concentrations (Korfali \& Jurdi, 2010), and its phytoplankton community. The reservoir water was fit for multipurpose uses, like drinking, domestic, recreational activities, irrigation, fisheries before 2000. Cylindrospermopsin, a cyanobacterial toxin was then detected in 2012 in the reservoir (Fadel et al., 2014a). Irrigation by water contaminated with this toxin affects the growth and productivity of seedlings like cucumber and tomato (Temsah et al., 2016). Recent climatic fluctuations and temperature increase have upset the biodiversity of Karaoun reservoir, resulting in blooms Microcystis aeruginosa and Aphanizomenon ovalisporum (Slim et al., 2014).

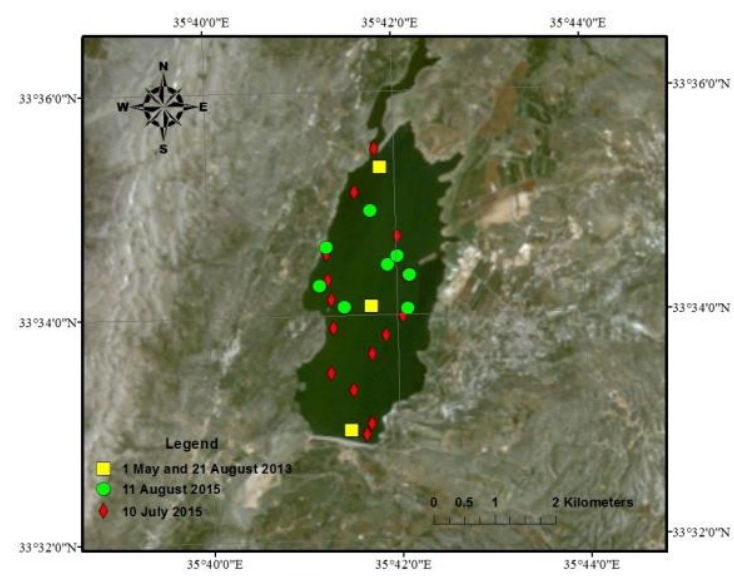

Figure 1. Sampling points at Karaoun reservoir. 


\section{Field sampling}

Four field campaigns were conducted in this study (Figure 1). One campaign (26 April 2013, $n=3$ ) was performed four days before the Landsat 8 overpass while the other three campaigns 21 August $2013(\mathrm{n}=3)$, 10 July $2015(\mathrm{n}=15)$, and 11 August $2015(\mathrm{n}=8)$, were performed during the Landsat 8 overpass. According to Krizanich and Finn 2009, field data collected on the same day as the satellite overpass result in the best regression results (Krizanich \& Finn, 2009). However, field data collected from 1 to 7 days off the satellite overpass date can still be used but can result in a decreasing strength of correlation (Chipman et al., 2004; Kloiber et al., 2002).

Water samples were collected at subsurface, at different locations throughout the reservoir (Figure 1). The position of the sampling boat was geolocated by a portable global positioning system (GPS). Samples were stored at $4^{\circ} \mathrm{C}$ until further processing in the laboratory. Subsamples were used for phytoplankton identification, turbidity analysis and chlorophyll-a quantification.

\section{Laboratory analysis}

The phytoplankton species were identified on the sampling day according to taxonomic keys based on cell structure and dimensions, colony morphology, and mucilage characteristics (Komárek \& Anagnostidis, 2005; 1999). Microscopic identifications were carried out under a phase contrast microscope (Nikon TE200, Nikon, Melville, New York, USA).

Chlorophyll-a quantification, used to estimate total phytoplankton biomass, was carried out according to Lorenzen method (Lorenzen, 1967). A duplicate of each sample was filtered using Whatman GF/C filters that were then kept frozen at $-20{ }^{\circ} \mathrm{C}$ for $16 \mathrm{~h}$. Chlorophyll-a was extracted from these filters in $90 \%$ acetone by ultrasonication and agitation. The extracts were centrifuged at $3500 \mathrm{rpm}$ for $10 \mathrm{~min}$ to reduce the turbidity. About $2 \mathrm{~mL}$ were used for chlorophyll-a quantification by spectrophotometry, then a correction was performed by adding $60 \mu \mathrm{L}$ of $0.1 \mathrm{M} \mathrm{HCl}$ to these $2 \mathrm{~mL}$ to measure the amount of chlorophyll-a degradation product, pheophytin-a.

Turbidity was only measured on 10 July and 11 August 2015 using a turbidity meter (ORION AQ3010, Thermo Scientific).

\section{Estimation of trophic state index}

To classify the evolution of trophic state of Karaoun Reservoir between 2013 and 2015, we applied Carlson's Trophic State Index (CTSI) that was calculated based on chlorophyll-a concentration (in mg. $\mathrm{m}^{-3}$ ), according to the following equation (Carlson, 1977):

$$
\operatorname{TSI}(C h l-a)=9.8 \ln C h l-a+30.6
$$

Based on the values of CTSI (Carlson, 1977; Sheela et al., 2011) freshwater bodies are classified as oligotrophic (CTSI less than 40), mesotrophic (CTSI between 40 and 50), eutrophic (CTSI between 50 and 70) or hypereutrophic (CTSI greater than 70). 


\section{Landsat OLI data}

The Landsat Data Continuity Mission's (LDCM), Landsat 8, launched on February 11, 2013, uses two sensor payload, the Operational Land Imager (OLI) and the Thermal InfraRed Sensor (TIRS) [refer to Iron et al., 2012 or to Roy et al., 2014]. It collects images of the entire earth every 16 days in an 8 days offset the Landsat-7. Landsat 8 Operational Land Imager (OLI) and Thermal Infrared Sensor (TIRS) images consist of nine spectral bands with a spatial resolution of 30 meters for Bands 1 to 7 and 9 . New band 1 (ultra-blue) is useful for coastal and aerosol studies (TABLE 1). Bands 6 and 7 (SWIR 1 and 2) cover different slices of the shortwave infrared, SWIR. They are particularly useful to discriminate moisture content of soil and vegetation. New band 9 is useful for cirrus cloud detection. The resolution for Band 8 (panchromatic) is 15 meters. Thermal bands 10 and 11 with a spatial resolution of 100 meters, are useful in providing more accurate surface temperatures (Loveland \& Dwyer, 2012). Approximate scene size is $170 \mathrm{~km}$ north-south by $183 \mathrm{~km}$ east-west (106 mi by 114 $\mathrm{mi}$ ). The OLI sensor has nine spectral bands between $0.43 \mu \mathrm{m}$ to $1.38 \mu \mathrm{m}$, consisting of seven multispectral bands, a panchromatic band and a cirrus band. The OLI multispectral bands have more advantage on Landsat-7 TM after the addition of two new spectral bands, band 1 for coastal water and aerosol, and band 9 for cirrus cloud detection.

Four cloud free images of path 174 and raw 37 are used in this study. These images were downloaded freely from the USGS website http://earthexplorer.usgs.gov/. They are Level $1 \mathrm{~T}$ processed, meaning that they have undergone systematic terrain calibration and geometric calibration. However, they need radiometric calibration and atmospheric correction to achieve the purpose of chlorophyll-a concentration retrieval. Those two procedures are conducted by the ENVI software in this work. Radiometric calibration was performed on all image data used in this work as recommended by the USGS website. An atmospherically correction was then done using the widely used method, FLAASH (Fast Line-of-sight Atmospheric Analysis of Hypercubes) provided by ENVI (Exelis, Boulder, CO), as shown in

Figure 2 (Nazeer et al., 2014; Souza Jr. et al., 2013; Vibhute et al., 2015).

TABLE 1

OLI and TIRS Specifications

\begin{tabular}{|c|c|c|}
\hline Bands & Wavelength $(\mu \mathrm{m})$ & Resolution $(\mathrm{m})$ \\
\hline Band 1 - Coastal aerosol & $0.43-0.45$ & 30 \\
Band 2 - Blue & $0.45-0.51$ & 30 \\
Band 3 - Green & $0.53-0.59$ & 30 \\
Band 4 - Red & $0.64-0.67$ & 30 \\
Band 5 - Near Infrared (NIR) & $0.85-0.88$ & 30 \\
Band 6 - SWIR 1 & $1.57-1.65$ & 30 \\
Band 7 - SWIR 2 & $2.11-2.29$ & 30 \\
Band 8 - Panchromatic & $0.50-0.68$ & 15 \\
Band 9 - Cirrus & $1.36-1.38$ & 30 \\
Band 10 - Thermal Infrared (TIRS) 1 & $10.60-11.19$ & $100 \mathrm{~m}$ resampled to \\
Band 11 - Thermal Infrared (TIRS) 2 & $11.50-12.51$ & $30 \mathrm{~m}$ \\
\end{tabular}




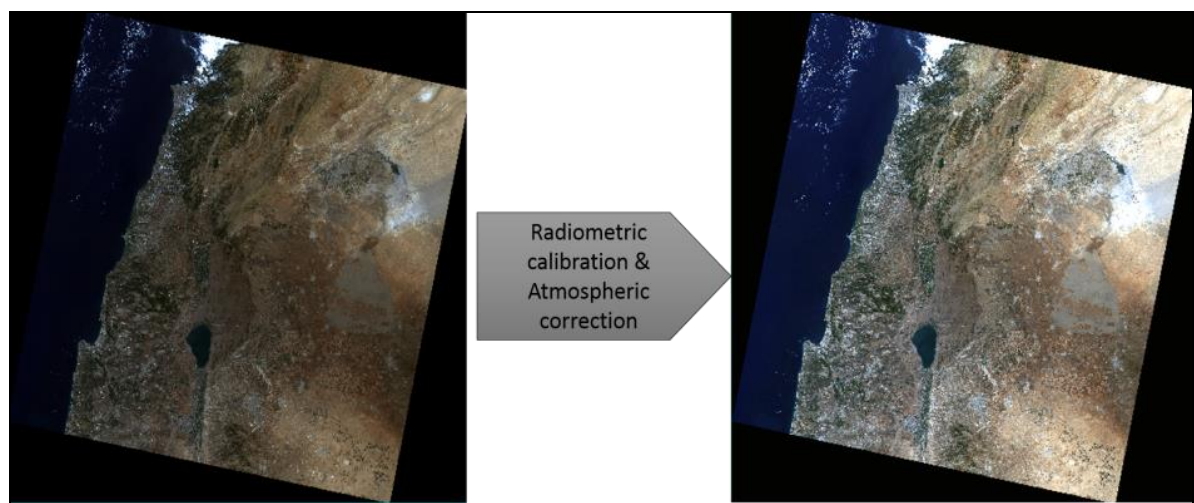

Figure 2. Image processing: radiometric calibration and atmospheric correction.

\section{Results and Discussion}

\section{Main identified species and in-situ chlorophyll-a}

The phytoplankton community identified in the different sampling dates used in this study was dominated by two cyanobacteria species (TABLE 2). As an overall, three phytoplankton groups were identified: diatoms (Aulacoseira granulate and Melosira varians), green algae (Botryococcus braunii, Volvox aureus, Pediastrum duplex, Staurastrum manfeldtii, Dictyosphaerium pulchellum, and Coelastrum microporum) and cyanobacteria (Microcystis aeruginosa, Anabaena circinalis and Aphanizomenon ovalisporum).

As indicated in previous studies (Slim et al., 2014), Microcystis aeruginosa and Aphanizomenon ovalisporum are still the main blooming cyanobacterial species in the reservoir. The succession of these toxic species is comparable to the year 2012 as reported by (Fadel et al. 2014b), with Aphanizomenon ovalisporum bloom at late Spring followed by a bloom of Microcystis aeruginosa in Summer. The biodiversity of phytoplankton community is very low in the reservoir that is often dominated by one genus of cyanobacteria group (TABLE 2).

\section{TABLE 2}

Species Identified under the Microscope in the Subsurface Samples Taken at the 4 Sampling Dates Used in this Study

\begin{tabular}{|c|c|c|c|}
\hline 26 April 2013 & 21 August 2013 & 10 July 2015 & 11 August 2015 \\
\hline $\begin{array}{c}\text { Botryococcus braunii } \\
\text { Volvox aureus } \\
\text { Coelastrum microporum } \\
\text { Aulacoseira granulate } \\
\text { Melosira varians }\end{array}$ & $\begin{array}{c}\text { Microcystis } \\
\text { aeruginosa }\end{array}$ & $\begin{array}{c}\text { Aphanizomenon } \\
\text { ovalisporum }\end{array}$ & $\begin{array}{l}\text { Microcystis } \\
\text { aeruginosa }\end{array}$ \\
\hline
\end{tabular}


Chlorophyll-a concentrations measured during the four sampling dates was wide in range, between 40 and $430 \mathrm{mg} \cdot \mathrm{m}^{-3}$ (Figure 3). Highest spatial variation of chlorophyll-a occurred in 10 July 2015 during a bloom event of cyanobacterium Aphanizomenon ovalisporum. This signifies that the use of a single station to monitor in situ chlorophyll-a at Karaoun reservoir is not sufficient in some bloom events as it may overestimate or underestimate chlorophyll-a concentrations when compared to chlorophyll-a averaged over the reservoir area. Based on previous studies on Karaoun Reservoir (Slim et al. 2014; Fadel et al. 2015), it is thought that low or no precipitation between May and October, in combination with decrease in water-level, thermal stratification, high nutrient concentrations, and cyanotoxin production results in a low biodiversity of the phytoplankton community in Karaoun reservoir.

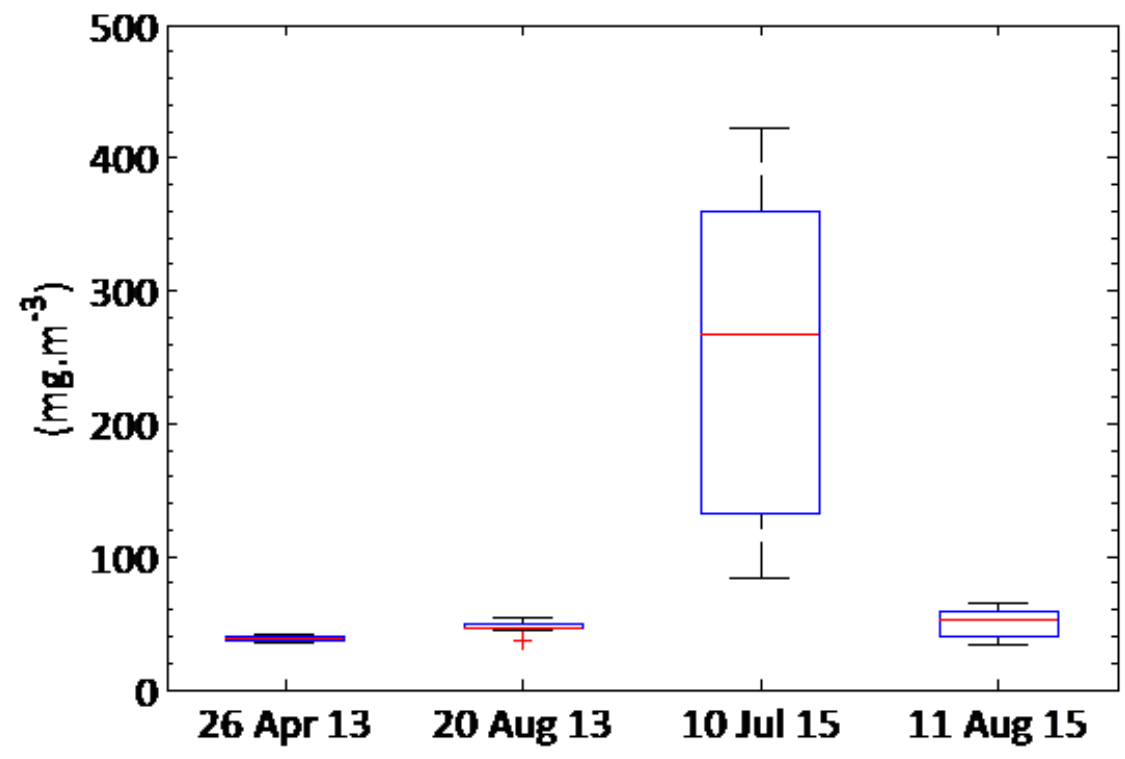

Figure 3. Chlorophyll-a concentrations measured during 26 April 2013, 20 Aug 2013, 10 July 2015 and 11 August 2015.

Turbidity measured during 10 July and 11 August 2015 ranged between 10 and 176 NTU. It was highly correlated with chlorophyll-a measurements, with $\mathrm{R}^{2}=0.94$ for wide range of chlorophyll-a concentrations, 36-423 mg.m $\mathrm{m}^{-3}$ (Figure 4). This signifies that phytoplankton community might be the major contributor to turbidity in the reservoir. Lower correlation of $\mathrm{R}^{2}=0.75$ was found for lower range of chlorophyll-a concentrations, $36-153 \mathrm{mg} \cdot \mathrm{m}^{-3}$ (Figure4). Karaoun Reservoir is a monomictic water body that strongly stratifies between May and August (Fadel et al., 2015). This prevents the resuspension of bottom sediment and the physical-chemical exchanges between the different layers of the water columns. Mixing of water occurs in fall or early winter when $\mathrm{T}$ of surface water lowers downs to become equivalent to the bottom water. No mixing is induced by the river inflow to the reservoir, because inflow rate is negligible between May and August each year due to no precipitation events (Assaf \& Saadeh, 2008). 
a)

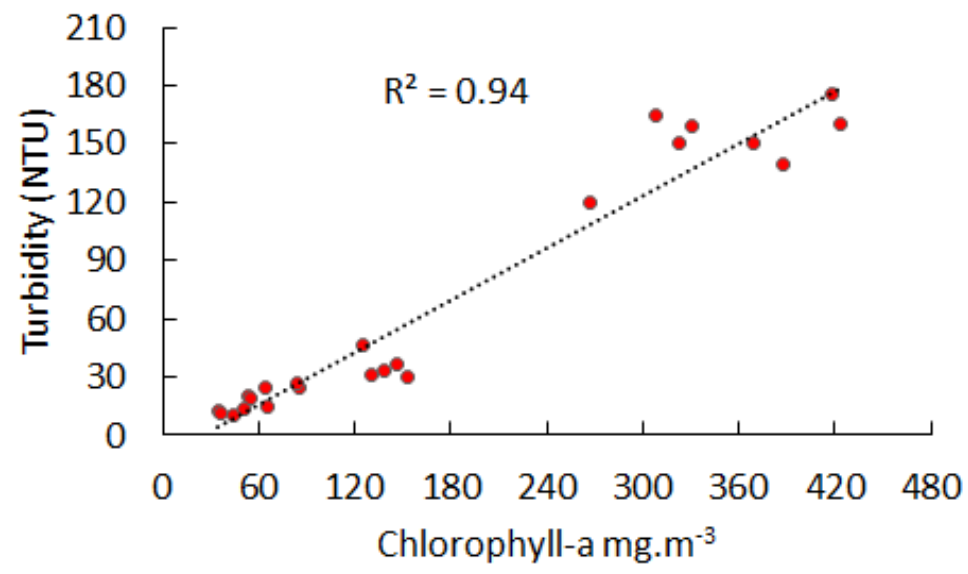

b)

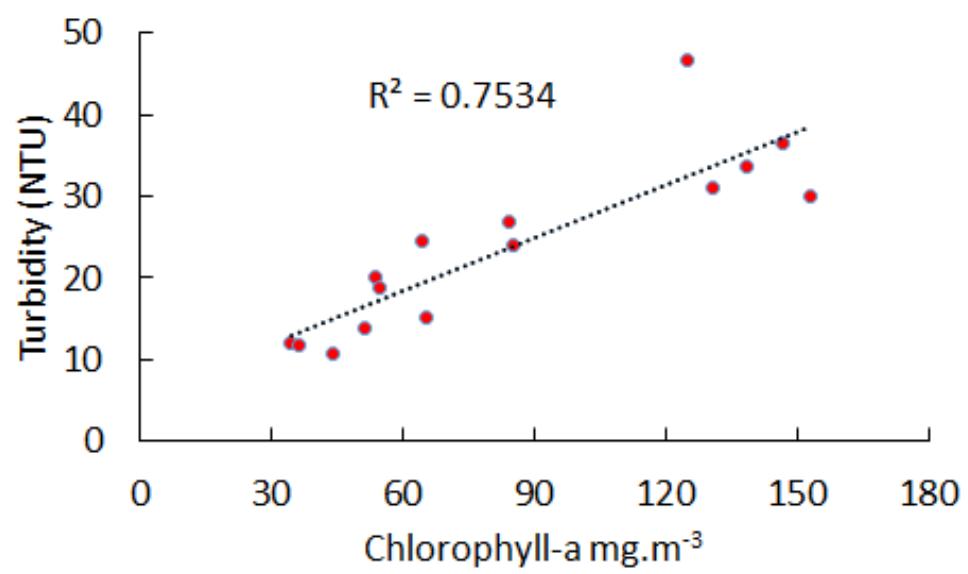

Figure 4. Correlation between chlorophyll-a and turbidity measurements during 10 July and 11 August 2015. a) high range of chlorophyll-a concentration, up to $480 \mathrm{mg} \cdot \mathrm{m}^{-3}(\mathrm{n}=$ 23 ) and b) lower range of chlorophyll-a concentration, up to $180 \mathrm{mg}^{-\mathrm{m}^{-3}}(\mathrm{n}=15)$.

\section{Trophic state in summer 2015}

The Carlson trophic state index of Karaoun reservoir during the 4 sampling dates in 2013 and 2015 is presented in Figure 5. CTSI ranged between 66 and 84. In 2013 the CTSI was less than 70, classifying the reservoir as eutrophic. The CTSI was much higher in 2015, above 70, classifying the reservoir as hypereutrophic. Previous studies performed on the reservoir in 2004, 2005 and 2010 classified the reservoir as eutrophic to hypereutrophic. Our results for 2013 and 2015 show that the reservoir trophic state has not improved during the last ten years (Figure 5). 
The agricultural activities and untreated industrial and municipal waste waters, increased number of inhabitants after the construction of several refugee camps and solid and liquid wastes dumped into the Litani River, pollute and deteriorate the water quality of Karaoun reservoir and increase its trophic state (Fadel, et al., 2014b). Reservoir managers in Karaoun reservoir should take actions that reduce the nutrient influx to the reservoir to improve its trophic state.

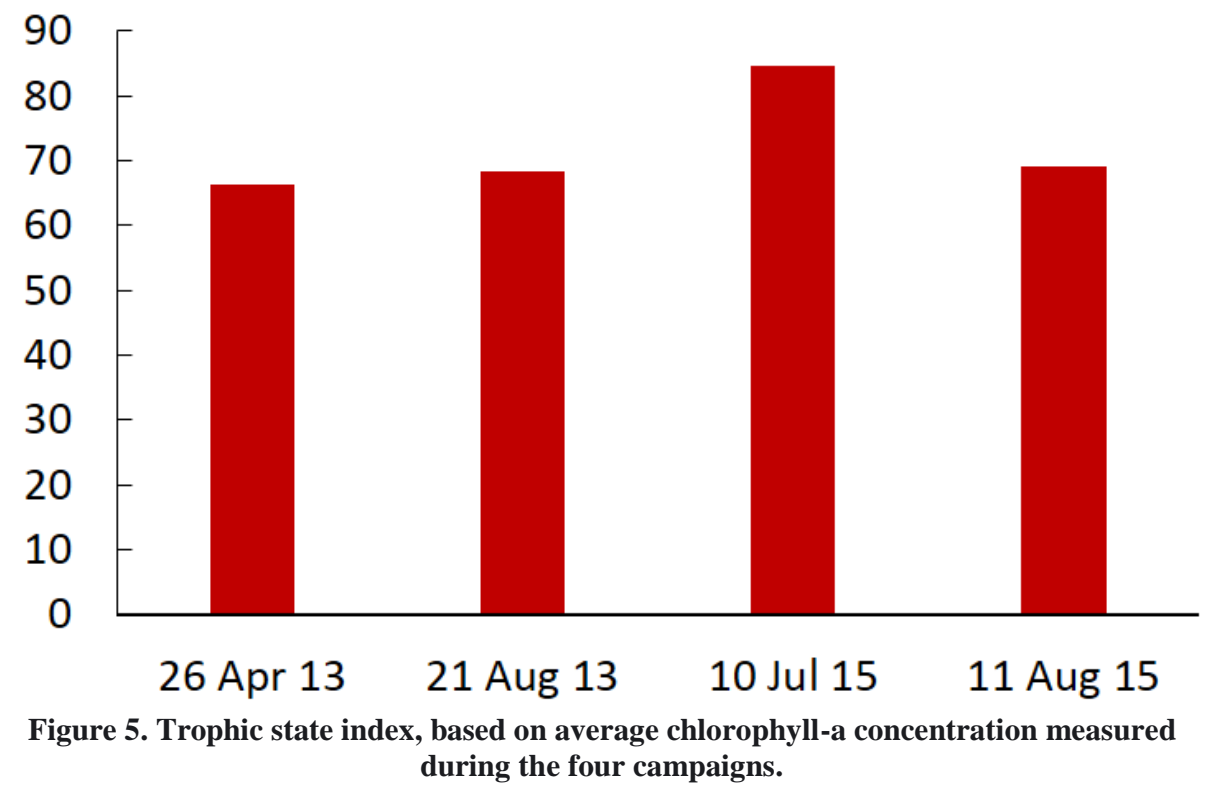

\section{Comparison to Landsat OLI data}

Linear regression relationships between in situ chlorophyll-a concentration and Landsat OLI bands 1-5 was performed in order to determine which Landsat single bands can be used to estimate chlorophyll-a concentration in Karaoun reservoir. On single band level, the in situ chlorophyll-a measurement correlated best with band 5, with $\mathrm{R}=0.75$ and $\mathrm{R}^{2}=0.57$ (Table 3 ). The lowest correlation, $\mathrm{R}=0.08$ and $\mathrm{R}^{2}=0.01$ was with band 4 .

Previous investigations (Brezonik et al., 2005; Duan et al., 2007) suggested that band combinations including ratios, multiplication and/or average might provide useful relationships to estimate chlorophyll-a concentration in inland waters. Many tested band combinations showed good correlation with in situ chlorophyll-a measurements. However, the best band combination with $\mathrm{R}=0.85$ and $\mathrm{R}^{2}=0.72$ was obtained for $\mathrm{B} 2$ : $\mathrm{B} 4$ band ratio multiplied with B5 (TABLE 3; Figure 6). 
TABLE 3

Linear Regression Relationships between In Situ Chlorophyll-a and Landsat OLI Bands $(\mathrm{n}=29)$

\begin{tabular}{|c|c|c|c|c|c|}
\hline Bands & $\mathbf{R}$ & $\mathbf{R} 2$ & Bands & $\mathbf{R}$ & $\mathbf{R 2}$ \\
\hline B1 & 0.34 & 0.11 & B5/B1 & 0.67 & 0.45 \\
\hline B2 & 0.32 & 0.1 & B5/B2 & 0.52 & 0.27 \\
\hline B3 & 0.12 & 0.015 & B5/B3 & 0.68 & 0.46 \\
\hline B4 & 0.08 & 0.01 & B5/B4 & 0.67 & 0.44 \\
\hline B5 & 0.75 & 0.57 & B1/B2*B5 & 0.76 & 0.58 \\
\hline B1*B2 & 0.33 & 0.11 & B1/B3*B5 & 0.83 & 0.68 \\
\hline B1*B3 & 0.22 & 0.05 & B1/B4*B5 & 0.84 & 0.71 \\
\hline B1*B4 & 0.16 & 0.02 & B1/B5*B5 & 0.34 & 0.11 \\
\hline B1*B5 & 0.77 & 0.58 & B2/B1*B5 & 0.69 & 0.47 \\
\hline B2*B3 & 0.18 & 0.03 & B2/B3*B5 & 0.82 & 0.66 \\
\hline B2*B4 & 0.13 & 0.02 & B2/B4*B5 & 0.84 & 0.72 \\
\hline B2*B5 & 0.71 & 0.5 & B2/B5*B5 & 0.32 & 0.1 \\
\hline B3*B4 & -0.01 & 0.01 & B3/B1*B5 & 0.48 & 0.23 \\
\hline B3*B5 & 0.51 & 0.29 & B3/B2*B5 & 0.55 & 0.3 \\
\hline B4*B5 & 0.52 & 0.27 & B3/B4*B5 & 0.77 & 0.6 \\
\hline B1*B2*B5 & 0.7 & 0.48 & B3/B5*B5 & 0.12 & 0.01 \\
\hline B1*B3*B5 & 0.58 & 0.33 & Average (B1;B2) & 0.33 & 0.11 \\
\hline B1*B4*B5 & 0.55 & 0.3 & Average (B1;B3) & 0.19 & 0.03 \\
\hline $\mathbf{B 2} * \mathbf{B} 3 * \mathbf{B 5}$ & 0.51 & 0.25 & Average (B1;B4) & 0.18 & 0.03 \\
\hline $\mathrm{B2} * \mathrm{~B} 4 * \mathrm{B5}$ & 0.49 & 0.24 & Average (B1;B5) & 0.71 & 0.5 \\
\hline $\mathrm{B3} * \mathrm{~B} 4 * \mathrm{B5}$ & 0.2 & 0.08 & Average (B2;B3) & 0.19 & 0.04 \\
\hline B1/B2 & -0.22 & 0.05 & Average (B2;B4) & 0.19 & 0.03 \\
\hline B1/B3 & -0.03 & 0.01 & Average (B2;B5) & 0.67 & 0.45 \\
\hline B1/B4 & -0.06 & 0.01 & Average (B3;B4) & 0.11 & 0.01 \\
\hline B1/B5 & -0.55 & 0.3 & Average (B3;B5) & 0.45 & 0.2 \\
\hline B2/B1 & 0.2 & 0.04 & Average (B4;B5) & 0.52 & 0.27 \\
\hline B2/B3 & 0.27 & 0.07 & Average(B1;B2;B5) & 0.62 & 0.39 \\
\hline B2/B4 & 0.32 & 0.1 & $\begin{array}{c}\text { Average (B1; B5)+ } \\
\text { Average (B2;B5) }\end{array}$ & 0.69 & 0.47 \\
\hline B2/B5 & -0.51 & 0.26 & Average (B2;B5) - B1 & 0.67 & 0.45 \\
\hline B3/B1 & -0.13 & 0.11 & Average $(\mathrm{B} 1 ; \mathrm{B5})$ - B2 & 0.68 & 0.46 \\
\hline B3/B2 & -0.27 & 0.15 & Average (B1;B5)+B1 & 0.58 & 0.35 \\
\hline B3/B4 & -0.07 & 0.03 & Average (B2;B5)+B1 & 0.58 & 0.34 \\
\hline B3/B5 & -0.53 & 0.17 & $2 *$ Average (B2;B5)-B1 & 0.71 & 0.5 \\
\hline B4/B1 & -0.11 & 0.01 & $2 *$ Average (B1;B2)-B5 & 0.47 & 0.22 \\
\hline B4/B2 & -0.32 & 0.1 & & & \\
\hline B4/B3 & 0.01 & 0.01 & & & \\
\hline B4/B5 & -0.6 & 0.36 & & & \\
\hline
\end{tabular}




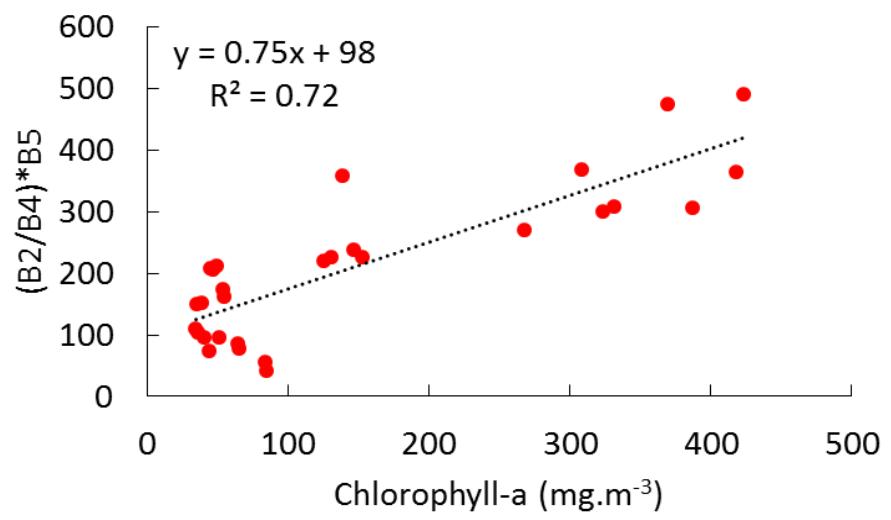

Figure 6. Correlation between In Situ chlorophyll-a and best band combination, $\mathrm{B} 2 / \mathrm{B} 4 * \mathrm{~B} 5, \mathrm{n}=29$.

The algorithm obtained between measured chlorophyll-a and the best band combination is shown in equation 1. This algorithm was applied to 1 May 2013 and 10 July 2015 to examine its precision in estimating chlorophyll-a throughout the reservoir. It was able to estimate the low concentration and homogenous distribution of chlorophyll-a during 1 May 2013 (Figure 7a and b). The algorithm also estimated correctly the high and heterogeneous distribution of chlorophyll-a during 10 July 2015 (Figure 7c and d).

$$
\text { Equation 1: } \quad C h l-a=\frac{\frac{B 2}{B 4} B 5-98}{0.75}
$$

Few studies were conducted on Landsat 8 that was launched recently, in 2013. Manzo et al. (2015), tried to describe the spectral sensitivity of the new remote sensing sensors, Landsat 8 to chlorophyll-a using the water reflectance simulated by analytical modelling. Their sensitivity results showed the effectiveness of Landsat 8 in chlorophyll-a analysis in meso-eutrophic and oligotrophic status.

Landsat OLI broad bands can make it difficult to spectrally resolve the prominent spectral features of water quality parameters as chlorophyll-a because it does not have a narrow band to target optical features associated with water quality parameters. However, Landsat bands may be correlated with chlorophyll-a through the total absorption and scattering properties (Kutser, 2009). The chlorophyll fluorescence peak at $683 \mathrm{~nm}$ is a special characteristic of harmful algal blooms which can be used to effectively separate it from other types of water (Shen et al., 2012). However, the chlorophyll-a absorption at red region of 670 $\mathrm{nm}$ is not totally presented in the OLI band 4 . The peak is also present around $700 \mathrm{~nm}$ and is totally out of the OLI bands (Table 1). Oki (2010) found that the chlorophyll-a concentration could be accurately estimated by using the ratio of spectral radiance reflectance of the red light region around $675 \mathrm{~nm}$ as the denominator and a near infrared region within the range of $700 \mathrm{~nm}$ through $730 \mathrm{~nm}$ as the numerator. This agrees with the algorithm we found, where the near infrared band 5 is a numerator and red light region band 4 is a denominator. 
a)
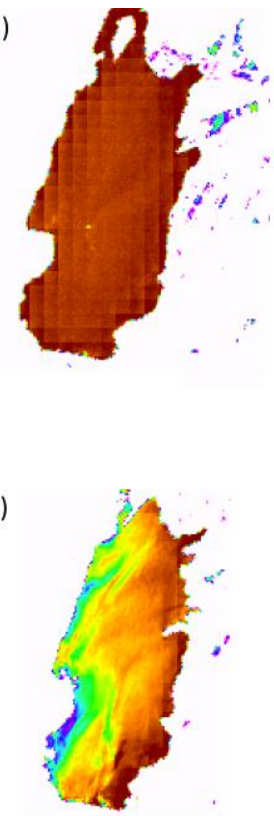

b)
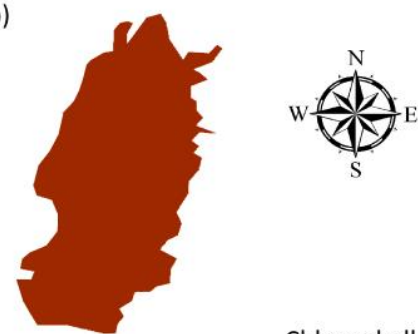

Chlorophyll-a

$\mathrm{mg} \cdot \mathrm{m}^{-3}$

d)

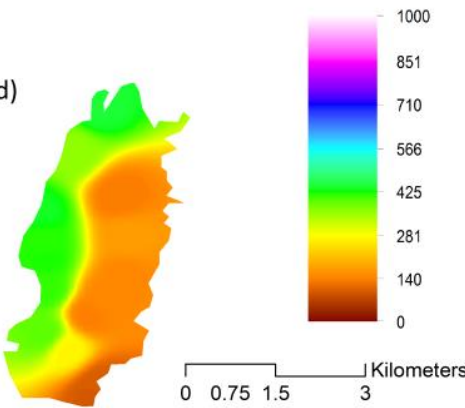

Figure 7. Comparison between estimated (a, c) and measured (b, d) chlorophyll in 1 May 2013 and 10 July 2015, respectively.

The reflectance peak varies according to the phytoplankton species. Not all phytoplankton species has their reflectance peak at $700 \mathrm{~nm}$. Some species has double peak rather than one single peak around $680-750 \mathrm{~nm}$. Other species have a wide peak from 680 to $900 \mathrm{~nm}$ (Shen et al., 2012). Spectral reflectance and absorption bands of Microcystis can be beyond $750 \mathrm{~nm}$. Maruthi Sridhar and Vincent (2007) found that Microcystis bloom in lake water had a minor absorption around $765 \mathrm{~nm}$ with a reflectance plateau of $780-810 \mathrm{~nm}$ in the near-infrared region. This reflectance gradually decreases from $810-1,000 \mathrm{~nm}$. This may explain why the OLI band 5 correlated the most with the phytoplankton biomass in our study. A three-band model developed by Duan et al. (2010), to estimate chlorophyll-a in eutrophic and turbid waters showed that a waveband intervals with $(\lambda 1>600 \mathrm{~nm}, \lambda 2>600 \mathrm{~nm}, \lambda 3>$ $750 \mathrm{~nm}$ ), with lower restrictions on wavelength optimization, provided higher determination coefficient and lower root mean squared error. Our results also shows that a 3 bands model that uses a ratio of any of the first 3 bands (1-3) to band 4, multiplied by band 5 provided the highest determination coefficient, $\mathrm{R}^{2} \geq 0.6$ (TABLE 3 ).

Chlorophyll-a concentrations in this study are relatively high. Figure 6 shows that the correlation between the in situ chlorophyll-a and the best bands combination is good for wide range of concentrations (36-423 $\mathrm{mg} \mathrm{m}^{-3}$ ). The correlation maybe not very strong in low range of chlorophyll-a concentration. This makes the best band combination limited to mesotrophic, eutrophic and hypereutrophic inland waters. For oligotrophic freshwater bodies, this band combination may still need to be tested and improved. 


\section{CONCLUSION}

The information presented in this study increases the knowledge about chlorophyll monitoring in case II waters using Landsat OLI mission. High spatial variation of chlorophylla concentration can occur in the reservoir. The assessment of the trophic state of Karaoun reservoir in 2013 and 2015 has shown that it is eutrophic to hypertrophic. The biodiversity of the phytoplankton community is low and is dominated by two cyanobacteria species, Aphanizomenon ovalisporum and Microcystis aeruginosa. Reservoir managers in Karaoun reservoir should take actions that reduce the nutrient influx to the reservoir to improve its trophic state.

We assessed the potentiality of Landsat OLI in determining chlorophyll-a concentration in Case II waters. A good correlation was found between OLI band 5 and measured chlorophyll-a concentrations in Karaoun reservoir. The use of band combination of B2:B4 band ratio multiplied with B5 resulted in best correlation with measured chlorophyll-a in our study and shows that Landsat OLI has the potential to be used for analysis of chlorophyll-a. This monitoring approach using Landsat OLI can be transposed and tested on other eutrophic lakes and reservoir throughout the world with different characteristics to verify its efficiency as cost effective method for the monitoring of phytoplankton biomass.

\section{ACKNOWLEDGMENTS}

This project has been funded with support from the National Council for Scientific Research - Lebanon.

\section{REFERENCES}

Assaf, H., Saadeh, M. 2008. Assessing water quality management options in the Upper Litani Basin, Lebanon, using an integrated GIS-based decision support system. Environ. Model. Softw., 23: 1327-1337.

Azevedo, S., Carmichael, W., Jochimsen, E., Rinehart, K. 2002. Human intoxication by microcystins during renal dialysis treatment in Caruara-Brazil. Toxicology, 181: 441-446.

Bresciani, M., Bolpagni, R., Laini, A., Matta, E., Bartoli, M. 2013. Multitemporal analysis of algal blooms with MERIS images in a deep meromictic lake. 445-458.

Brezonik, P., Menken, K.D., Bauer, M. 2005. Landsat-based Remote Sensing of Lake Water Quality Characteristics, Including Chlorophyll and Colored Dissolved Organic Matter (CDOM). Lake Reserv. Manag., 21: 373-382.

Brient, L., Lengronne, M., Bormans, M., Fastner, J. 2009. First occurrence of cylindrospermopsin in freshwater in France. Environ. Toxicol., 24: 415-420.

Carlson, R.E. 1977. A trophic state index for lakes. Limnol. Oceanogr., 22: 261-369.

Chipman, J.W., Lillesand, T.M., Schmaltz, J.E., Leale, J.E., Nordheim, M.J. 2004. Mapping lake water clarity with Landsat images in Wisconsin, U.S.A. Can. J. Remote Sens., 30: $1-7$.

Chorus, I. 2005. Water safety plans: A better regulatory approach to prevent human exposure to harmful cyanobacteria., In: J. Huisman, H.C.P. Matthijs (Eds.), harmful cyanobacteria. Springer. pp. 201-227.

Codd, G., Bell, S., Kaya, K., Ward, C., Beattie, K., Metcalf, J. 1999. Cyanobacterial toxins, exposure routes and human health. Eur. J. Phycol., 34: 405-415. 
Duan, H., Ma, R., Xu, J., Zhang, Y., Zhang, B. 2010. Comparison of different semi-empirical algorithms to estimate chlorophyll-a concentration in inland lake water. Environ. Monit. Assess., 170: 231-244.

Duan, H., Zhang, Y., Zhang, B., Song, K., Wang, Z. 2007. Assessment of chlorophyll-a concentration and trophic state for Lake Chagan using Landsat TM and field spectral data. Environ. Monit. Assess., 129: 295-308.

European Parliament Council 2000. Directive 2000/ 60/EC of the European Parliament and of the council of 23 October 2000 establishing a framework for community action in the field of water policy. Off. J. Eur. Communitie., L327: 1-72.

Fadel, A., Atoui, A., Lemaire, B., Vinçon-Leite, B., Slim, K. 2014a. Dynamics of the toxin cylindrospermopsin and the cyanobacterium Chrysosporum (Aphanizomenon) ovalisporum in a Mediterranean eutrophic reservoir.. Toxins (Basel), 6: 3041-3057.

Fadel, A., Lemaire, B.J., Atoui, A., Vinçon-Leite, B., Amacha, N., Slim, K., Tassin, B. 2014b. First assessment of the ecological status of Karaoun Reservoir, Lebanon. Lakes Reserv. Res. Manag., 19: 142-157.

Fadel, A., Atoui, A., Lemaire, B.J., Vinçon-Leite, B., Slim, K. 2015. Environmental factors associated with phytoplankton succession in a Mediterranean reservoir with a highly fluctuating water level. Environ. Monit. Assess., 187: 633.

Gerace, A., Schott, J. 2009. The increased potential for the Landsat Data Continuity Mission to contribute to case 2 water quality studies. In: Butler, J.J., Xiong, X., Gu, X. (Eds.) Proc. SPIE 7452, Earth Observing Systems. International Society for Optics and Photonics. p. 74520U-74520U-11.

Irons, J.R., Dwyer, J.L., Barsi, J.A. 2012. The next Landsat satellite: The Landsat Data Continuity Mission. Remote Sens. Environ., 122: 11-21.

Kabenge, M., Wang, H., Li, F. 2016. Urban eutrophication and its spurring conditions in the Murchison Bay of Lake Victoria. Environ. Sci. Pollut. Res. Int., 23: 234-241.

King, M.D., Kaufman, Y.J., Menzel, W.P., Tanre, D. 1992. Remote sensing of cloud, aerosol, and water vapor properties from the moderate resolution imaging spectrometer (MODIS). IEEE Trans. Geosci. Remote Sens., 30: 2-27.

Kloiber, S.M., Brezonik, P.L., Olmanson, L.G., Bauer, M.E. 2002. A procedure for regional lake water clarity assessment using Landsat multispectral data. Remote Sens. Environ., 82: 38-47.

Komárek, J., Anagnostidis, K. 2005. Cyanoprokaryota 2 Teil: Oscillatoriales. Büdel, B., Gärtner, G., Krienitz, L. \& Schagerl, M (eds), Süßwasserflora von Mitteleuropa Band 19/2, Spektrum Akademischer Verlag (Elsevier).

Komárek, J., Anagnostidis, K. 1999. Cyanoprokaryota 1 Teil: Chroococcales. Ettl, H., Gärtner, G., Heynig, G.H. \& Mollenhauer, D. (eds), Süßwasserflora von Mitteleuropa Band 19/1, Spektrum Akademischer Verlag.

Korfali, S., Jurdi, M. 2010. Speciation of metals in bed sediments and water of Qaraaoun Reservoir, Lebanon. Environ. Monit. Assess., 178: 563-579.

Krizanich, G.W., Finn, M.P. 2009. Table rock lake water-clarity assessment using landsat thematic mapper satellite data, U.S. Geological Survey Scientific Investigations Report 2009. 5162.

Kutser, T. 2009. Passive optical remote sensing of cyanobacteria and other intense phytoplankton blooms in coastal and inland waters. Int. J. Remote Sens., 30: 44014425.

Li, P., Jiang, L., Feng, Z. 2013. Cross-Comparison of Vegetation Indices Derived from Landsat-7 Enhanced Thematic Mapper Plus (ETM+) and Landsat-8 Operational Land Imager (OLI) Sensors. Remote Sens., 6: 310-329. 
Lorenzen, C.J. 1967. Determination of chlorophyll and phaeo-pigments: spectrophotometric equations. Limnol. Ocean., 12: 343-346.

Loveland, T.R., Dwyer, J.L. 2012. Landsat: Building a strong future. Remote Sens. Environ., 122: 22-29.

Manzo, C., Bresciani, M., Giardino, C., Braga, F., Bassani, C. 2015. Sensitivity analysis of a bio-optical model for Italian lakes focused on Landsat-8, Sentinel-2 and Sentinel-3. Eur. J. Remote Sens., 48: 17-32.

Maruthi Sridhar, B.B., Vincent, R.K. 2007. Spectral Reflectance Measurements of a Microcystis Bloom in Upper Klamath Lake, Oregon. J. Great Lakes Res., 33: 279284.

Nazeer, M., Nichol, J.E., Yung, Y.-K. 2014. Evaluation of atmospheric correction models and Landsat surface reflectance product in an urban coastal environment.

Nyakairu, G.W.A., Nagawa, C.B., Mbabazi, J. 2010. Assessment of cyanobacteria toxins in freshwater fish: A case study of Murchison Bay (Lake Victoria) and Lake Mburo, Uganda. Toxicon., 55: 939-946.

Odermatt, D., Giardino, C., Heege, T. 2010. Remote Sensing of Environment Chlorophyll retrieval with MERIS Case-2-Regional in perialpine lakes. Remote Sens. Environ., 114: 607-617.

Oki, K., 2010. Why is the ratio of reflectivity effective for chlorophyll estimation in the lake water? Remote Sens., 2: 1722-1730.

Rast, M., Bezy, J.L., Bruzzi, S. 1999. The ESA Medium Resolution Imaging Spectrometer MERIS a review of the instrument and its mission. Int. J. Remote Sens., 20: 16811702.

Sheela, A.M., Letha, J., Joseph, S. 2011. Environmental status of a tropical lake system. Environ. Monit. Assess., 180: 427-449.

Shen, L., Xu, H., Guo, X., 2012. Satellite remote sensing of harmful algal blooms (HABs) and a potential synthesized framework. Sensors (Basel), 12: 7778-7803.

Slim, K., Fadel, A., Atoui, A., Lemaire, B.J., Vinçon-Leite, B. Tassin, B., 2014. Global warming as a driving factor for cyanobacterial blooms in Lake Karaoun, Lebanon. Desalin. Water Treat., 52: 2094-2101.

Smith, V.H., Schindler, D.W. 2009. Eutrophication science: where do we go from here? Trends Ecol. Evol., 24: 201-207.

Song, K., Li, L., Tedesco, L., Clercin, N., Hall, B., Li, S., Shi, K., Liu, D., Sun, Y. 2013. Remote estimation of phycocyanin (PC) for inland waters coupled with YSI PC fluorescence probe. Environ. Sci. Pollut. Res. Int., 20: 5330-40.

Souza, Jr. C., Siqueira, J., Sales, M., Fonseca, A., Ribeiro, J., Numata, I., Cochrane, M., Barber, C., Roberts, D., Barlow, J. 2013. Ten-year Landsat classification of deforestation and forest degradation in the Brazilian Amazon. Remote Sens., 5: 5493-5513.

Temsah, M., Tarhini, K., Fadel, A., Slim, K. 2016. Effect of irrigation with lake water containing cylindrospermopsin toxin on seed germination and seedlings growth of Cucumis sativus and Lycopersicon esculatum. Int. J. Sci. Basic Appl. Res., 27: 108122.

Vibhute, A.D., Kale, K. V, Dhumal, R.K., Mehrotra, S.C. 2015. Hyperspectral imaging data atmospheric correction challenges and solutions using QUAC and FLAASH algorithms. 2015 Int. Conf. Man Mach. Interfacing.

Wu, G., De Leeuw, J., Skidmore, A.K., Prins, H.H.T., Liu, Y. 2008. Comparison of MODIS and Landsat TM5 images for mapping tempo-spatial dynamics of Secchi disk depths in Poyang Lake National Nature Reserve, China. Int. J. Remote Sens., 29: 
2183-2198.

Wu, T., Qin, B., Zhu, G., Luo, L., Ding, Y., Bian, G. 2013. Dynamics of cyanobacterial bloom formation during short-term hydrodynamic fluctuation in a large shallow, eutrophic, and wind-exposed Lake Taihu, China. Environ. Sci. Pollut. Res., 20: 8546-8556. 